\title{
Paecilaminol, a New NADH-Fumarate Reductase Inhibitor, Produced by Paecilomyces sp. FKI-0550
}

\author{
Hideaki Ui, Kazuro Shiomi, Hideaki Suzuki, Hiroko Hatano, Hiromi Morimoto, \\ Yuichi Yamaguchi, Rokuro Masuma, Kimitoshi Sakamoto, Kiyoshi Kita, \\ Hideto Miyoshi, Hiroshi Tomoda, Haruo Tanaka, Satoshi Ōmura
}

Received: July 12, 2006 / Accepted: August 24, 2006

(C) Japan Antibiotics Research Association

\begin{abstract}
A new NADH-fumarate reductase inhibitor, paecilaminol, was isolated from the cultured broth of a fungus Paecilomyces sp. FKI-0550. It is an amino alcohol compound, the structure being established as 2-amino14,16-dimethyl-3-octadecanol. Paecilaminol exhibited an $\mathrm{IC}_{50}$ value of $5.1 \mu \mathrm{M}$ against Ascaris suum NADHfumarate reductase.
\end{abstract}

Keywords paecilaminol, electron transport enzyme inhibitor, NADH-fumarate reductase

\section{Introduction}

Microorganisms produce many useful antiparasitic antibiotics [1]. In the course of screening for anthelmintic antibiotics, we have been interested in the differences in energy metabolisms between the host and helminths [2]. The NADH-fumarate reductase (NFRD) system, which is found in many anaerobic organisms, is part of a special respiratory system in parasitic helminths [3]. The system is composed of complex I (NADH-rhodoquinone oxidoreductase) and complex II (rhodoquinol-fumarate oxidoreductase). Electrons from NADH are accepted by rhodoquinone through complex I, and then transferred to fumarate through complex II. This anaerobic electron transport system can provide ATP in the absence of oxygen. During our screening for inhibitors of NFRD using Ascaris suum (roundworm) mitochondria, we obtained both nafuredin and atpenins. Nafuredin is a selective inhibitor of helminth complex I which showed anthelmintic activity in vivo $[4,5]$. Atpenins are complex II inhibitors, and the inhibition is non-selective between helminths and mammals [6]. They are the most potent complex II inhibitors and are expected to be useful tools for biochemical studies.

Further screening for NFRD inhibitors led to the isolation of a new compound, paecilaminol (1, Fig. 1), which was produced by a cultured broth of Paecilomyces sp. FKI-0550 [7]. In this report, we describe the taxonomy of the producing strain and the fermentation, isolation, structure elucidation, and biological properties of $\mathbf{1}$.
K. Shiomi (Corresponding author), S. Ōmura (Corresponding author), H. Ui, R. Masuma: Kitasato Institute for Life Sciences and Graduate School of Infection Control Sciences, Kitasato University, 5-9-1 Shirokane, Minato-ku, Tokyo 108-8641, Japan, E-mail: shiomi@lisci.kitasato-u.ac.jp and omura-s@kitasato.or.jp H. Morimoto, H. Tomoda: School of Pharmaceutical Sciences, Kitasato University, 5-9-1 Shirokane, Minato-ku, Tokyo 1088641, Japan
K. Shiomi, H. Suzuki, H. Hatano, Y. Yamaguchi, H. Tanaka, S. Ōmura: The Kitasato Institute, 5-9-1 Shirokane, Minato-ku, Tokyo 108-8642, Japan

K. Sakamoto, K. Kita: Department of Biomedical Chemistry, Graduate School of Medicine, The University of Tokyo, Hongo, Bunkyo-ku, Tokyo 113-0033, Japan

H. Miyoshi: Division of Applied Life Sciences, Graduate School of Agriculture, Kyoto University, Kitashirakawa Oiwake-cho, Sakyo-ku, Kyoto 606-8502, Japan 
<smiles>CCCCCCCCCCCCC/C=C/[C@H](O)[C@@H](N)CO</smiles><smiles>[X][C@H](O)[C@@H](C)N(C)CCCCCCC/C=C/CCC</smiles>

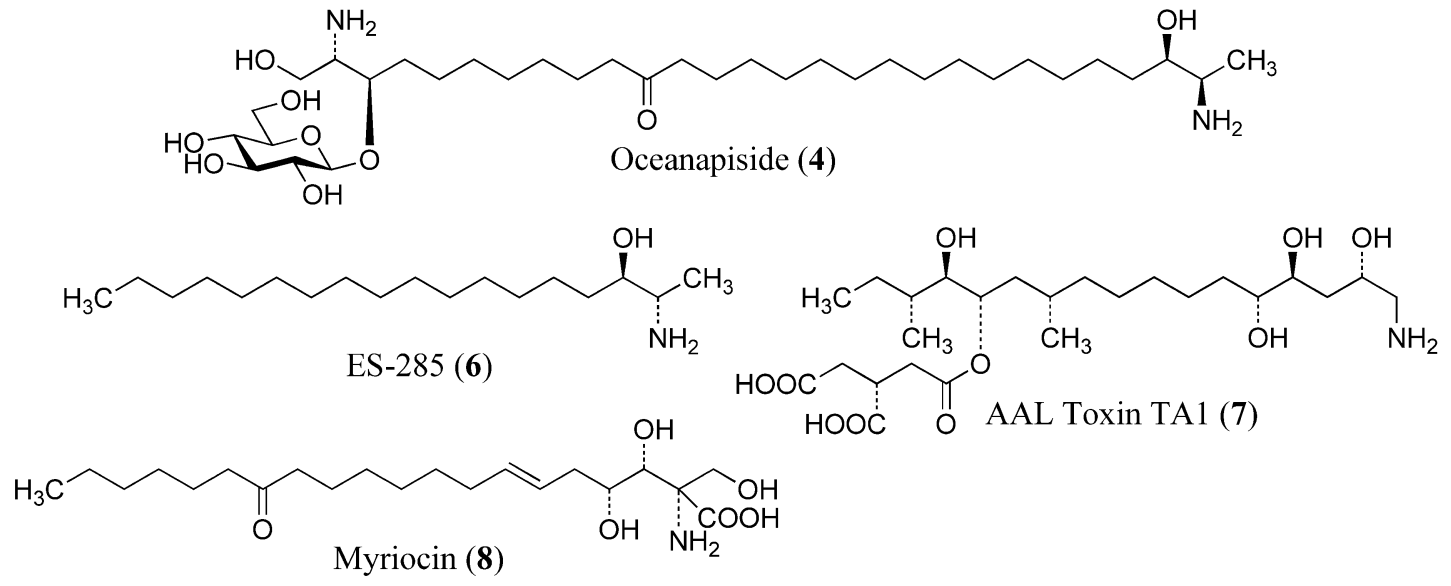

Fig. 1 Structures of paecilaminol (1) and related amino alcohols (2 $\sim 8)$.

\section{Results and Discussion}

\section{Taxonomy of Producing Strain FKI-0550}

Strain FKI-0550 was originally isolated from a soil sample collected on Miyakojima Island, Okinawa Prefecture, Japan. The strain was taxonomically determined as genus Paecilomyces sp. The strain has been deposited at the International Patent Organism Depositary, National Institute of Advanced Industrial Science and Technology, Tsukuba, Japan, as FERM BP-7785.

\section{Fermentation and Isolation of Paecilaminol}

A stock culture of the strain FKI-0550 was inoculated into two 500-ml Erlenmeyer flasks containing $100 \mathrm{ml}$ of a seed medium and incubated on a rotary shaker at $27^{\circ} \mathrm{C}$ for 3 days. One milliliter of the seed culture was transferred into each of one hundred 500-ml Erlenmeyer flasks containing $100 \mathrm{ml}$ of a production medium. The fermentation was carried out on a rotary shaker at $27^{\circ} \mathrm{C}$ for 9 days.

Mycelia were collected from the cultured broth (10 liters) by centrifugation. They were treated with methanol, the extract removed and the methanol was evaporated. The

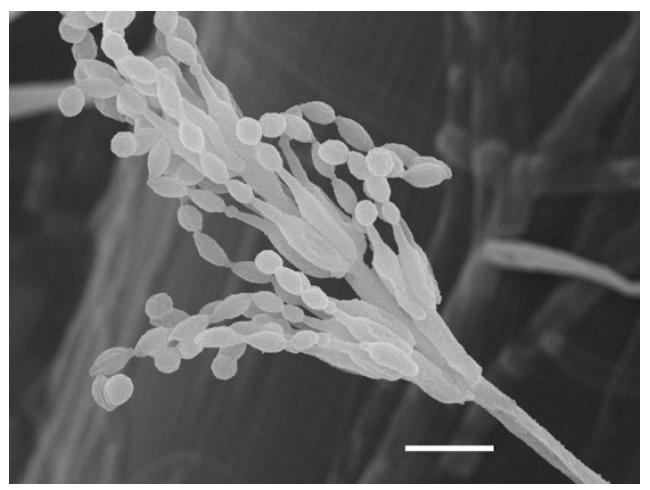

Fig. 2 Scanning electron micrograph of strain FKI-0550. Bar represents $5 \mu \mathrm{m}$.

aqueous extract was partitioned with ethyl acetate, and the organic layer was concentrated to dryness in vacuo to afford a crude material (461 mg). This was applied on a silica gel column (Merck Art. 7734) and washed with $\mathrm{CHCl}_{3}$-methanol $(10: 1)$. Active fractions eluted with $\mathrm{CHCl}_{3}$ - methanol $(1: 1)$ were concentrated to yield a crude material $(120 \mathrm{mg})$, which was then chromatographed over another silica gel column. The column was washed with 
ethyl acetate and eluted with ethyl acetate-methanol concd $\mathrm{NH}_{4} \mathrm{OH}(80: 9: 1)$. The elution afforded a pale yellow oil of $1(70.1 \mathrm{mg})$.

\section{Structure Elucidation of Paecilaminol}

Physico-chemical properties of $\mathbf{1}$ are summarized in Table 1. The molecular formula of $\mathbf{1}$ was established as $\mathrm{C}_{20} \mathrm{H}_{43} \mathrm{NO}$ by HR-FAB-MS. The IR absorbances observed at $2958,2924,2852,1464$, and $1377 \mathrm{~cm}^{-1}$ suggested the presence of saturated methyl and methylene groups. The absorbance at $1574 \mathrm{~cm}^{-1}$ suggested an amino group, and the absorbances at 3300 and $1080 \mathrm{~cm}^{-1}$ suggested a hydroxyl and/or amino group. As the index of hydrogen deficiency of $\mathbf{1}$ was $0, \mathbf{1}$ was suggested to be an alkyl amino alcohol. This was further supported by the analysis of IR absorbances.

Chemical shifts of $\mathbf{1}$ in the ${ }^{1} \mathrm{H}$ and ${ }^{13} \mathrm{C}$ NMR are shown in Table 2. Analysis of the ${ }^{1} \mathrm{H}$ NMR, ${ }^{13} \mathrm{C}$ NMR, DEPT, and HMQC spectra revealed the presence of four methine, twelve methylene, and four methyl carbons. ${ }^{1} \mathrm{H}-{ }^{1} \mathrm{H}-\mathrm{COSY}$ of 1 indicated the presence of 3-amino-2-hydroxybutyl (C1 to $\mathrm{C}-4)$ and 2,4-dimethylhexyl (C-13 to $\mathrm{C}-18)$ moieties (Fig. 3). Long-range couplings from $3-\mathrm{H}(\delta 3.16)$ and $4-\mathrm{H}_{2}$

Table 1 Physico-chemical properties of 1

\begin{tabular}{lll}
\hline Appearance & & pale yellow oil \\
{$[\alpha]_{D}^{25}$} & & $+26.7^{\circ}(c 0.24, \mathrm{MeOH})$ \\
Molecular formula & $\mathrm{C}_{20} \mathrm{H}_{43} \mathrm{NO}$ \\
Molecular weight & & 313.57 \\
HR-FAB-MS $(m / z)$ & found & $314.3424(\mathrm{M}+\mathrm{H})^{+}$ \\
& calcd & 314.3423 for $\mathrm{C}_{20} \mathrm{H}_{44} \mathrm{NO}$ \\
$\mathrm{UV} \lambda_{\max }^{\mathrm{MeOH}} \mathrm{nm}(\varepsilon)$ & & $203(8,250), 220(\mathrm{sh}, 4,400), 246$ \\
& & $(2,040), 265(\mathrm{sh}, 1,570)$ \\
IR $v_{\max }(\mathrm{KBr}) \mathrm{cm}^{-1}$ & & $3300,2958,2924,2852,1574$, \\
& & $1464,1377,1080$ \\
Solubility & soluble & $\mathrm{CHCl}_{3}, \mathrm{EtOAc}, \mathrm{MeOH}, \mathrm{CH}_{3} \mathrm{CN}$ \\
& insoluble & $n$-hexane \\
Color reaction & positive & ninhydrin, $\mathrm{H}_{2} \mathrm{SO}_{4}$ \\
\hline
\end{tabular}

( $\delta 1.33$ and 1.46$)$ to $\mathrm{C}-5$ ( $\delta$ 25.8) suggested the bond between $\mathrm{C}-4$ and $\mathrm{C}-5$, and the couplings from $13-\mathrm{H}_{2}$ $(\delta 1.01$ and 1.26$)$ and $14-\mathrm{H}(\delta 1.45)$ to $\mathrm{C}-12(\delta 26.9)$ suggested the bond between $\mathrm{C}-12$ and $\mathrm{C}-13$ in HMBC. Though the remaining six methylenes could not be assigned as their protons showed almost the same chemical shifts, they should be linked to the two moieties. Thus, the structure of 1 was elucidated as 2-amino-14,16-dimethyl-3octadecanol (Fig. 1). After our patent publication [7], 1 was reported to be isolated from Fusarium avenaceum as a cytotoxic compound [8].

Table $2{ }^{1} \mathrm{H}$ and ${ }^{13} \mathrm{C}$ data (in $\mathrm{CDCl}_{3}$ ) of $\mathbf{1}^{a}$

\begin{tabular}{|c|c|c|}
\hline Position & $\delta_{\mathrm{C}}$ (mult) & $\delta_{\mathrm{H}}($ int, $J(\mathrm{~Hz}))$ \\
\hline 1 & $20.9 q$ & $1.09 \mathrm{~d}(3 \mathrm{H}, 6.3)$ \\
\hline 2 & $51.1 d$ & $2.72 \mathrm{dq}(1 \mathrm{H}, 6.4,6.3)$ \\
\hline 3 & $75.6 d$ & $3.16 \mathrm{~m}(1 \mathrm{H})$ \\
\hline 4 & $34.2 \mathrm{t}$ & $1.33 \mathrm{~m}(1 \mathrm{H}), 1.46 \mathrm{~m}(1 \mathrm{H})$ \\
\hline 5 & $25.8 t$ & $1.33 \mathrm{~m}(1 \mathrm{H}), 1.46 \mathrm{~m}(1 \mathrm{H})$ \\
\hline 6 & $30.03^{b} \mathrm{t}$ & \\
\hline $7 \sim 10$ & $\begin{array}{l}29.62 t \\
29.63 t \\
29.65 t \\
29.69 t\end{array}$ & $1.25 \mathrm{~m}(12 \mathrm{H})$ \\
\hline 11 & $29.8^{b} t$ & \\
\hline 12 & $26.9 \mathrm{t}$ & $1.26 \mathrm{~m}(2 \mathrm{H})$ \\
\hline 13 & $36.9 t$ & $1.01 \mathrm{~m} \mathrm{(1H),} 1.26 \mathrm{~m}(1 \mathrm{H})$ \\
\hline 14 & $30.01 \mathrm{~d}$ & $1.45 \mathrm{~m}(1 \mathrm{H})$ \\
\hline $14-\mathrm{CH}_{3}$ & $20.3 q$ & $0.82 \mathrm{~d}(3 \mathrm{H}, 6.6)$ \\
\hline 15 & $44.7 t$ & $0.88 \mathrm{ddd}(1 \mathrm{H}, 14.0,7.0,7.0), 1.20 \mathrm{~m}(1 \mathrm{H})$ \\
\hline 16 & $31.6 d$ & $1.40 \mathrm{~m}(1 \mathrm{H})$ \\
\hline $16-\mathrm{CH}_{3}$ & $19.7 q$ & $0.82 \mathrm{~d}(3 \mathrm{H}, 6.6)$ \\
\hline 17 & $29.2 \mathrm{t}$ & $1.05 \mathrm{~m}(1 \mathrm{H}), 1.33 \mathrm{~m}(1 \mathrm{H})$ \\
\hline 18 & $11.2 \mathrm{q}$ & $0.84 \mathrm{dd}(3 \mathrm{H}, 7.4,7.4)$ \\
\hline
\end{tabular}

${ }^{a}$ NMR spectra were recorded on a Varian Inova 600 spectrometer. Chemical shifts are shown in $\delta$ values (ppm) relative to $\mathrm{CDCl}_{3}$ at $7.26 \mathrm{ppm}$ for ${ }^{1} \mathrm{H}$ NMR and at $77.0 \mathrm{ppm}$ for ${ }^{13} \mathrm{C} \mathrm{NMR}$.

${ }^{b}$ The chemical shifts are interchangeable.

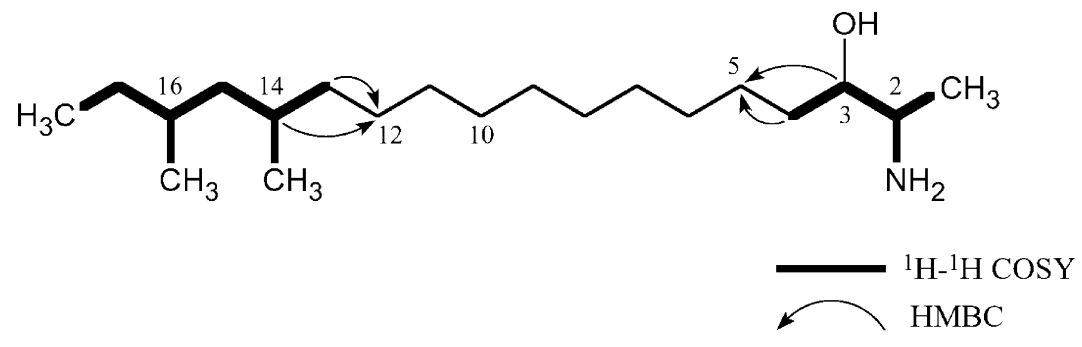

Fig. 3 Selected ${ }^{1} \mathrm{H}-{ }^{1} \mathrm{H}$ COSY and HMBC correlations of $\mathbf{1}$. 
Table 3 Inhibition of electron transport enzymes by 1

\begin{tabular}{lcr}
\hline \multicolumn{1}{c}{ Enzyme } & Complex & $I_{50}(\mu \mathrm{M})$ \\
\hline NADH-fumarate reductase (A. suum) & I+II & 5.1 \\
NADH oxidase (bovine heart) & I+III+IV & 19.8 \\
NADH-rhodoquinone oxidoreductase (A. suum SMP) & I & 23 \\
Rhodoquinol-fumarate oxidoreductase (A. suum SMP) & II & 35 \\
NADH-ubiquinone oxidoreductase (bovine heart SMP) & I & 16 \\
Succinate-ubiquinone oxidoreductase (bovine heart SMP) & II & 20 \\
Ubiquinol-cytochrome c oxidoreductase (bovine heart SMP) & III \\
\hline
\end{tabular}

\section{Biological Activities of Paecilaminol}

Though the A. suum NFRD inhibitory activity of 1 was moderate $\left(\mathrm{IC}_{50}=5.1 \mu \mathrm{M}\right.$, Table 3$)$, the inhibition was about 4 times more potent than that of bovine heart NADH oxidase (complexes I+III+IV). In the screening of NFRD inhibitors, we added $30 \mathrm{mg} / \mathrm{ml}$ of bovine serum albumin to the NFRD assay system to eliminate the effect of nonspecific inhibition by fatty acids and acylglycerols. It is interesting that bovine serum albumin did not affect the NFRD inhibition of $\mathbf{1}\left(\mathrm{IC}_{50}=3.2 \mu \mathrm{M}\right)$. Generally, it reduced NFRD inhibition significantly. In the case of nafuredin, inhibition was reduced about 100 -fold by bovine serum albumin.

We evaluated inhibitory activities of $\mathbf{1}$ against each complex using submitochondrial particles (SMP) of $A$. suum and bovine heart (Table 3). Compound 1 inhibited NADH-rhodoquinone oxidoreductase (complex I) and rhodoquinol-fumarate oxidoreductase (complex II) of A. suum SMP in similar concentration. It also inhibited NADH-ubiquinone oxidoreductase (complex I) and ubiquinol-cytochrome $c$ oxidoreductase (complex III) of bovine heart SMP in similar concentration. However, the inhibition against bovine succinate-ubiquinone oxidoreductase (complex II) was weak. Therefore, 1 showed similar inhibitory activities against complexes I, II, and III of A. suum and bovine heart, except bovine complex II. It is not common for electron transport inhibitors to show such low selectivity. The only group that shows such wide inhibitions are the 2-alkyl-4,6-dinitrophenols, but their inhibitory activity against complex II is also weaker than that for complexes I and III [9]. The low selectivity of 1 may be due to its linear structure, because both amino and hydroxyl groups can freely rotate and be attached to enzymes.

Compound $\mathbf{1}$ is an amino alcohol, and its structure is similar to sphingosine (2), a long-chain base of sphingolipids. However, NFRD inhibition of $\mathbf{2}$ was very weak (Table 4). Fumonisin $B_{1}$ (3) [10], a fungal amino
Table 4 NFRD inhibition by compounds related to 1

\begin{tabular}{lr}
\hline \multicolumn{1}{c}{ Enzyme } & $\mathrm{IC}_{50}(\mu \mathrm{M})$ \\
\hline Sphingosine (2) & 28 \\
Fumonisin $\mathrm{B}_{1}(\mathbf{3})$ & $>100$ \\
2-Decanol & $>100$ \\
\hline
\end{tabular}

Table 5 Antimicrobial activity of $\mathbf{1}$

\begin{tabular}{lc}
\hline \multicolumn{1}{c}{ Microorganisms } & MIC $(\mu \mathrm{g} / \mathrm{ml})$ \\
\hline Staphylococcus aureus ATCC6538P & 12.5 \\
Bacillus subtilis ATCC6633 & 6.25 \\
Micrococcus luteus ATCC9341 & 6.25 \\
Mycobacterium smegmatis ATCC607 & 25 \\
Escherichia coli NIHJ & $>100$ \\
Escherichia coli IFO12734 & $>100$ \\
Pseudomonas aeruginosa IFO3080 & $>100$ \\
Xanthomonas campestris pv. oryzae KB88 & $>100$ \\
Candida albicans KF1 & $>100$ \\
Saccharomyces cerevisiae KF26 & $>100$ \\
Aspergillus niger ATCC6275 & 100 \\
Mucor racemosus IFO4581 & 100 \\
\hline
\end{tabular}

alcohol, did not inhibit NFRD at $100 \mu \mathrm{M}$. A simple alcohol 2-decanol also showed no inhibition against NFRD at $100 \mu \mathrm{M}$.

Nematocidal and insecticidal activities of $\mathbf{1}$ were studied by a microplate assay using free-living nematode Caenorhabditis elegans and brine shrimp Artemia salina. Minimum growth inhibitory concentrations of $\mathbf{1}$ against $C$. elegans and $A$. salina were $20 \mu \mathrm{g} / \mathrm{ml}$ and $5 \mu \mathrm{g} / \mathrm{ml}$, respectively. As shown in Table 5, it exhibited moderate antimicrobial activity against Gram-positive bacteria.

Though $\mathbf{2}$ is a 2-aminoalkene with 1,3-diol residues, $\mathbf{1}$ 
lacks 1-hydroxyl residue. Such 2-amino-3-alkanols or 2amino-3-alkenols have been isolated from natural origins. Most of them were obtained from marine sponges, such as xestoaminols A $\sim \mathrm{C}$ isolated from Xestospongia sp. [11] and oceanapiside (4) isolated from Oceanapia phillipensis [12]. Xestoaminol A (5) showed nematocidal, antibacterial, and antifungal activity and inhibited reverse transcriptase [11]. Compound 4 showed antifungal activity [12]. It also exhibits inhibitory activity against a mycobacterial detoxification enzyme, mycothiol-S-conjugate amidase [13]. ES-285 (spisulosine 285, 6) was isolated from the clam Mactromeris polynyma, and it disrupts the cytoskeleton of cancer cells [14]. Compound $\mathbf{6}$ may decrease the activity of the GTP-binding protein Rho. It is currently being evaluated in phase I clinical trials for advanced solid tumors. Fumonisins are fungal 2-amino-3alkanols produced by Fusarium verticillioides. They are toxic and carcinogenic for animals and humans as a contaminant of grains $[10,15]$. The analogous compounds, AAL toxins (AAL Toxin TA1=7), are 1-amino-2-alkanols and produced by the phytopathogenic fungus Alternaria alternata f. sp. lycopersici [16]. Both mycotoxins inhibit ceramide synthase (sphingosine $N$-acyltransferase) $[15,17]$. Myriocin (ISP-I, 8) is a 2-aminoalkan-1,3-diol compound produced by fungi, Myriococcum albomyces and Isaria sinclairii [18, 19]. It is a potent immunosuppressant inhibiting serine palmitoyltransferase, the enzyme that catalyzes the first step of sphingolipid biosynthesis [19, 20]. The derivative of $\mathbf{8}$, FTY720, is in phase II clinical trials as an immunosuppressant [21].

As described above, amino alcohols have various biological activities. However, only a few have been reported to have an effect on electron transport enzymes. Galactosylsphingosine (psychosine), glucosylsphingosine, and 2 showed more than 50\% inhibition against complex IV (cytochrome $c$ oxidase) at $5 \mu \mathrm{M}$ [22]. Though $3 \%$ of bovine serum albumin did not affect the NFRD inhibition of $1,1 \%$ of human serum albumin completely abolished complex IV inhibition of $\mathbf{2}$ and its glycosides [22]. As for complex I, $\mathrm{N}$-acetylsphingosine and $\mathrm{N}$-palmitoylsphingosine were reported to inhibit the enzyme [23]. However, the inhibition was weak $\left(\mathrm{IC}_{50}=20 \sim 40 \mu \mathrm{M}\right)$, which is comparable with the NFRD inhibition of $\mathbf{2}$. Therefore, $\mathbf{1}$ is the first amino alcohol that has NFRD inhibitory activity.

\section{Experimental}

\section{General}

NMR spectra were recorded on a Varian Inova 600 spectrometer $\left({ }^{2-3} J_{\mathrm{CH}}=8 \mathrm{~Hz}\right.$ in $\left.\mathrm{HMBC}\right)$. Chemical shifts are shown in $\delta$ values (ppm) relative to $\mathrm{CDCl}_{3}$ at $7.26 \mathrm{ppm}$ for ${ }^{1} \mathrm{H}$ NMR and at $77.0 \mathrm{ppm}$ for ${ }^{13} \mathrm{C}$ NMR. Mass spectrometry was conducted on a JEOL JMS-AX505 HA spectrometer. The UV and IR spectra were measured with a Shimadzu UV-240 spectrophotometer and a Horiba FT-210 Fourier transform infrared spectrometer, respectively. Optical rotations were recorded on a JASCO model DIP-181 polarimeter.

\section{Taxonomic Studies of the Producing Organism}

Morphological observations of the paecilaminol producing strain were carried out using an Olympus Vanox-S AH-2 microscope and a JEOL JSM-5600 scanning electron microscope.

\section{Media}

The seed medium consisted of glucose $2.0 \%$, Polypepton (Nihon Pharmaceutical Co.) 0.5\%, yeast extract (Oriental Yeast Co.) $0.2 \%, \mathrm{KH}_{2} \mathrm{PO}_{4} 0.1 \%, \mathrm{MgSO}_{4} \cdot 7 \mathrm{H}_{2} \mathrm{O} 0.05 \%$, and agar $0.1 \%, \mathrm{pH}$ 5.7. The production medium consisted of glycerol $2.0 \%$, sucrose $1.0 \%$, ammonium acetate $0.5 \%, \mathrm{KH}_{2} \mathrm{PO}_{4} 0.1 \%, \mathrm{MgSO}_{4} \cdot 7 \mathrm{H}_{2} \mathrm{O} 0.05 \%, \mathrm{KCl} 0.05 \%$, Cultivater \#100 (fish extract, Yaizu Suisankagaku Industry Co.) $0.2 \%$, and agar $0.1 \%$, pH 6.0 .

\section{Biological Studies}

NFRD activity was measured as described previously [24]. The other enzyme assays were performed as described previously [4]. The assay method for nematocidal and insecticidal activities was reported previously [25]. The antimicrobial activity was measured by agar dilution method.

Acknowledgements We are grateful to Dr. Achim Harder of Bayer HealthCare AG, Animal Health-Research \& DevelopmentParasiticides for valuable discussions. We also thank Ms. Akiko Nakagawa and Ms. Chikako Sakabe of School of Pharmaceutical Sciences, Kitasato University for measurements of mass spectra. This work was supported by a Grant-in-Aid for Scientific Research (14593006 to K.S. and 13854011 to K.K.) and a Grantin-Aid for Encouragement of Young Scientists (12771373 to H.U.). This work was also supported in part by the Grant of the 21st Century COE Program, Ministry of Education, Culture, Sports, Science, and Technology.

\section{References}

1. Shiomi K, Ōmura S. Antiparasitic agents produced by microorganisms. Proc Jpn Acad, Ser B 80: 245-258 (2004)

2. Komuniecki R, Tielens AGM. Carbohydrate and energy 
metabolism in parasitic helminths. In Molecular Medical Parasitology. Ed. J. J. Marr, et al., pp. 339-358. Academic Press, London (2003)

3. Kita K, Nihei C, Tomitsuka E. Parasite mitochondria as drug target: diversity and dynamic changes during the life cycle. Curr Med Chem 10: 2535-2548 (2003)

4. Ōmura S, Miyadera H, Ui H, Shiomi K, Yamaguchi Y, Masuma R, Nagamitsu T, Takano D, Sunazuka T, Harder A, Kölbl H, Namikoshi M. Miyoshi H, Sakamoto K, Kita K. An anthelmintic compound, nafuredin, shows selective inhibition of complex I in helminth mitochondria. Proc Natl Acad Sci USA 98: 60-62 (2001)

5. Ui H, Shiomi K, Yamaguchi Y, Masuma R, Nagamitsu T, Takano D, Sunazuka T, Namikoshi M, Ōmura S. Nafuredin, a novel inhibitor of NADH-fumarate reductase, produced by Aspergillus niger FT-0554. J Antibiot 54: 234-238 (2001)

6. Miyadera H, Shiomi K, Ui H, Yamaguchi Y, Masuma R, Tomoda H, Miyoshi H, Osanai A, Kita K, Ōmura S. Atpenins, potent and specific inhibitors of mitochondrial complex II (succinate-ubiquinone oxidoreductase). Proc Natl Acad Sci USA 100: 473-477 (2003)

7. Ōmura S, Shiomi K, Masuma R. (The Kitasato Institute). Novel substance FKI-0550 manufacture with Paecilomyces. PCT Int Appl, WO 2003048373, June 12 (2003)

8. Uhlig S, Petersen D, Flåøyen A, Wilkins A. 2-Amino-14,16dimethyloctadecan-3-ol, a new sphingosine analogue toxin in the fungal genus Fusarium. Toxicon 46: 513-522 (2005)

9. Tan AK, Ramsay RR, Singer TP, Miyoshi H. Comparison of the structures of the quinone-binding sites in beef heart mitochondria. J Biol Chem 268: 19328-19333 (1993)

10. Gelderblom WCA, Jaskiewicz K, Marasas WFO, Thiel PG, Horak RM, Vleggaar R, Kriek NPJ. Fumonisins-novel mycotoxins with cancer-promoting activity produced by Fusarium moniliforme. Appl Envir Microbiol 54: 1806-1811 (1988)

11. Jiménez C, Crews P. Novel marine sponge amino acids, 10. Xestoaminols from Xestospongia sp. J Nat Prod 53: 978-982 (1990)

12. Nicholas GM, Hong TW, Molinski TF, Lerch ML, Cancilla MT, Lebrilla CB. Oceanapiside, an antifungal bis- $\alpha, \omega$ amino alcohol glycoside from the marine sponge Oceanapia phillipensis. J Nat Prod 62: 1678-1681 (1999)

13. Nicholas GM, Eckman LL, Newton GL, Fahey RC, Ray S, Bewley CA. Inhibition and kinetics of Mycobacterium tuberculosis and Mycobacterium smegmatis mycothiol-Sconjugate amidase by natural product inhibitors. Bioorg Med Chem 11: 601-608 (2003)

14. Cuadros R, Montejo de Garcini E, Wandosell F, Faircloth G, Fernandez-Sousa JM, Avila J. The marine compound spisulosine, an inhibitor of cell proliferation, promotes the disassembly of actin stress fibers. Cancer Lett 152: 23-29 (2000)

15. Merrill AH Jr, Wang E, Gilchrist DG, Riley RT. Fumonisins and other inhibitors of de novo sphingolipid biosynthesis. In Advances in Lipid Research Vol. 26. Sphingolipids. Part B: Regulation and Function of Metabolism. Ed. R. M. Bell, et al., pp. 215-234. Academic Press, San Diego (1993)

16. Bottini AT, Bowen JR, Gilchrist DG. Phytotoxins. II. Characterization of a phytotoxic fraction from Alternaria alternata f. sp. lycopersici. Tetrahedron Lett 22: 2723-2726 (1981)

17. Desai K, Sullards MC, Allegood J, Wang E, Schmelz EM, Hartl M, Humpf H-U, Liotta DC, Peng Q, Merrill AH Jr. Fumonisins and fumonisin analogs as inhibitors of ceramide synthase and inducers of apoptosis. Biochim Biophy Acta 1585: 188-192 (2002)

18. Kluepfel D, Bagli J, Baker H, Charest MP, Kudelski A, Sehgal SN, Vezina C. Myriocin, a new antifungal antibiotic from Myriococcum albomyces. J. Antibiot 25: 109-115 (1972)

19. Fujita $\mathrm{T}$, Inoue $\mathrm{K}$, Yamamoto $\mathrm{S}$, Ikumoto $\mathrm{T}$, Sasaki $\mathrm{S}$, Toyama R, Chiba K, Hoshino Y, Okumoto T. Fungal metabolites. Part 11. A potent immunosuppressive activity found in Isaria sinclairii metabolite. J. Antibiot 47: 208-215 (1994)

20. Miyake Y, Kozutsumi Y, Nakamura S, Fujita T, Kawasaki T. Serine palmitoyltransferase is the primary target of a sphingosine-like immunosuppressant, ISP-1/myriocin. Biochem Biophys Res Commun 211: 396-403 (1995)

21. Tedesco-Silva H, Mourad G, Kahan BD, Boira JG, Weimar W, Mulgaonkar S, Nashan B, Madsen S, Charpentier B, Pellet P, Vanrenterghem Y. FTY720, a novel immunomodulator: efficacy and safety results from the first phase $2 \mathrm{~A}$ study in de novo renal transplantation. Transplantation 77: 1826-1833 (2004)

22. Igisu $\mathrm{H}$, Hamasaki $\mathrm{N}$, Ito $\mathrm{A}, \mathrm{Ou} \mathrm{W}$. Inhibition of cytochrome $c$ oxidase and hemolysis caused by lysosphingolipids. Lipids 23: 345-348 (1988)

23. Di Paola M, Cocco T, Lorusso M. Ceramide interaction with the respiratory chain of heart mitochondria. Biochemistry 39: 6660-6668 (2000)

24. Shiomi K, Ui H, Suzuki H, Hatano H, Nagamitsu T, Takano D, Miyadera H, Yamashita T, Kita K, Miyoshi H, Harder A, Tomoda H, Ōmura S. A $\gamma$-lactone form nafuredin, nafuredin- $\gamma$, also inhibits helminth complex I. J Antibiot 58: 50-55 (2005)

25. Enomoto Y, Shiomi K, Matsumoto A, Takahashi Y, Iwai Y, Harder A, Kölbl H, Woodruff HB, Ōmura S. Isolation of a new antibiotic oligomycin G produced by Streptomyces sp. WK-6150. J Antibiot 54: 308-313 (2001) 